\title{
Eficácia in vitro de desinfetantes utilizados na anti-sepsia dos tetos frente a leveduras isoladas do leite de vaca com mastite ${ }^{1}$
}

\author{
Luciana C.A. Coutinho ${ }^{2}$, Elizabeth S. Medeiros ${ }^{3}$, Norma Suely. S. Silveira ${ }^{4}$, \\ Leonildo B.G. Silva ${ }^{2}$ e Rinaldo A. Mota $^{2 *}$
}

\begin{abstract}
Coutinho L.C.A., Medeiros E.S., Silveira N.S.S., Silva L.B.G. \& Mota R.A. 2012. [In vitro efficacy of disinfectants used for antisepsis of teats against yeasts isolated from milk of dairy cows with mastitis.] Eficácia in vitro de desinfetantes utilizados na anti-sepsia dos tetos frente a leveduras isoladas do leite de vaca com mastite. Pesquisa Veterinária Brasileira 32(1):61-65. Departamento de Medicina Veterinária, Universidade Federal Rural de Pernambuco, Av. Dom Manuel de Medeiros s/n, Dois Irmãos, Recife, PE 52171-900, Brazil. E-mail: rinaldo.mota@hotmail.com

The aim of this study was to evaluate in vitro sensibility of yeast isolated from milk of dairy cows with mastitis against some commercial disinfectants used in pre and post-dipping in dairy farms of the State of Pernambuco. After identification, 12 yeast isolates were tested with the following disinfectants: iodine at $0,57 \%$, chlorine at $2,5 \%$, chlorhexidine, lactic acid and quaternary ammonium at 2,0\%, at different exposure times. It was observed that $100 \%$ of the isolates were sensitive to chlorhexidine at all exposure times. Iodine has obtained the second best result with the following percentages: $83,33 \%$ were susceptible at $15^{\prime \prime}$ exposure, $91,7 \%$ in 30 " and $100 \%$ were sensitive at 60 " 300 " and 600 " times. For lactic acid, the results were $41,67 \%$ sensitive at $15^{\prime \prime}$ of exposure, $58,33 \%$ at 30 ", $66,7 \%$ at 60 " and $300 "$ and $75 \%$ at 600 ". In the analysis of the results for quaternary ammonium, it was observed that $66,67 \%$ were sensitive in $15^{\prime \prime}$ and $30^{\prime \prime}$ times and $91,67 \%$ at $60 ", 300$ " and 600 ". Regarding the chlorine activity, only $16,67 \%$ were sensitive at the $15^{\prime \prime}$ and 30 " times, and $25 \%$ at $60^{\prime \prime}, 300^{\prime \prime}$ and $600 "$. It was concluded that chlorhexidine and iodine have disinfectant activity significantly superior to chlorine, against to yeast involved in infectious processes of the mammary gland in cattle. It is necessary to perform a periodic assessment of the disinfectant activity from products used in the pre and post-dipping routine against dairy farms microorganisms most commonly involved in cases of mastitis (bacterial or fungal) which is an effective alternative to reduce the frequency of mastitis in cattle.
\end{abstract}

INDEX TERMS: Yeast, Candida, disinfectant, mastitis, milking.

RESUMO.- Objetivou-se com este estudo avaliar a sensibilidade in vitro de leveduras isoladas do leite de vaca com mastite frente a alguns desinfetantes comerciais utilizados

\footnotetext{
${ }^{1}$ Recebido em 29 de julho de 2011.

Aceito para publicação em 14 de setembro de 2011.

${ }^{2}$ Departamento de Medicina Veterinária, Universidade Federal Rural de Pernambuco (UFRPE), Avenida Dom Manuel de Medeiros s/n, Dois Irmãos, Recife, PE 52171-900, Brasil. *Autor para correspondência: rinaldo.mota@hotmail.com

${ }^{3}$ Universidade Federal de Alagoas, Unidade Educacional de Viçosa, Campus Arapiraca, Av. Manoel Severino Barbosa s/n, Bom Sucesso, Arapiraca, AL 57309-005, Brasil.

${ }^{4}$ Departamento de Biologia, Laboratório de Micologia, UFRPE, Dois Irmãos, Recife, PE.
}

no pré e pós-dipping em propriedades leiteiras do Estado de Pernambuco. Após a identificação, 12 isolados de leveduras foram submetidos aos testes com os seguintes princípios ativos: iodo $(0,57 \%)$, cloro $(2,5 \%)$, clorexidine $(2,0 \%)$, ácido láctico $(2,0 \%)$ e amônia quaternária $(2,0 \%)$ em cinco tempos distintos (15", 30", 60", 300" e 600"). Observou-se que $100 \%$ dos isolados mostraram-se sensíveis ao clorexidine, em todos os tempos de exposição. 0 iodo obteve o segundo melhor resultado com os seguintes percentuais: 83,33\% foram sensíveis em 15" de exposição, 91,67\% em 30 " e $100 \%$ foram sensíveis nos tempos $60 ", 300 "$ e 600 ". Para o ácido láctico, os resultados foram: $41,67 \%$ sensíveis em 15" de exposição, 58,33\% em 30", 66,67\% em 60" e $300 "$ e $75 \%$ em $600 "$. Na Análise dos resultados para amô- 
nia quaternária, observou-se que $66,67 \%$ foram sensíveis nos tempos $15^{\prime \prime}$ e 30 ", e $91,67 \%$ em $60 ", 300 "$ e $600 "$. Em relação ao princípio ativo cloro apenas $16,67 \%$ foram sensíveis no tempo de $15^{\prime \prime}$ e 30 ", e $25 \%$ em $60 ", 300$ " e 600 ". Conclui-se que o clorexidine e o iodo apresentam atividade desinfetante significativamente superior ao cloro, frente a leveduras envolvidas nos processos infecciosos da glândula mamária em bovinos. É necessário realizar uma avaliação periódica da atividade desinfetante dos produtos utilizados na rotina do pré e pós-dipping nas propriedades leiteiras frente aos microrganismos mais comumente envolvidos nos casos de mastite (micótica ou bacteriana), pois esta é uma medida eficaz para reduzir a frequência de casos de mastite nos rebanhos.

TERMOS DE INDEXAÇ̃̃o: Levedura, Candida, desinfetante, mastites, ordenha.

\section{INTRODUÇÃO}

O uso excessivo de antibióticos para tratar os casos de mastites bacterianas vem produzindo uma seleção da microbiota que beneficia a condição de leveduras, principalmente as do gênero Candida (Rey et al. 1997) a atuarem como agentes etiológicos das infecções intramamárias (Garcia \& Blanco 2000). A incidência das mastites micóticas em bovinos, ovinos e caprinos vem aumentando nos últimos anos, coincidindo com a frequente utilização de antibacterianos. As infecções intramamárias por fungos geralmente estão relacionadas à contaminação de cânulas intramamárias, ao manuseio do ordenhador ou diretamente do ambiente (Andrade 2002). Clinicamente, as mastites causadas por fungos são semelhantes às mastites bacterianas, mas a sintomatologia é bastante variável com um ou mais quartos acometidos (Cruz 1985).

0 controle da mastite, seja ela de origem micótica ou bacteriana, deve ter como base os métodos preventivos, tornando-se essencial a implementação de medidas relacionadas a um manejo correto e a protocolos de higiene na ordenha (Spanamberg et al. 2009). A exploração moderna e tecnificada da pecuária leiteira utiliza várias ferramentas que ajudam a manter um estado sanitário satisfatório do rebanho para a obtenção de leite e derivados lácteos que se enquadrem dentro dos padrões microbiológicos considerados adequados pela legislação vigente. 0 uso dos desinfetantes nas práticas de higiene da exploração leiteira é um costume antigo e ainda atual, que desempenha uma função muito importante na rentabilidade da fazenda, contribuindo para a produção de alimentos lácteos de alto padrão e para a obtenção de um rebanho sadio (Fonseca \& Santos 2000). No entanto, variações no perfil de sensibilidade e resistência dos microrganismos envolvidos nos processos infecciosos da glândula mamária de animais de produção leiteira podem comprometer os programas de controle da mastite (Medeiros et al. 2009).

Sá (1996) define desinfetantes como todo agente biológico, físico capaz 'de exercer uma ação nociva aos microrganismos e impedir a sua sobrevivência. Entretanto, os desinfetantes podem apresentar pouca eficácia quando na presença de matéria orgânica, sujidades ou urina, difi- cultando desta forma a atuação eficaz do produto (Quinn 1991). A anti-sepsia pós-ordenha tem como finalidade reduzir a população bacteriana na pele do teto e controlar a colonização do orifício da glândula mamária (Fox 1992). Este procedimento tem sido amplamente recomendado e adotado por constituir uma medida prática, econômica e eficaz no controle da mastite bovina (Pankey 1984). A anti-sepsia pré-ordenha é particularmente recomendada em propriedades leiteiras com problemas de mastite ambiental (Costa et al. 1998).

Tendo em vista a importância da escolha de um produto eficaz para a desinfecção dos tetos, objetivou-se com este estudo avaliar a eficácia in vitro de alguns princípios ativos (desinfetantes) utilizados no pré e pós-dipping frente a leveduras isoladas do leite de vacas com mastite.

\section{MATERIAL E MÉTODOS}

Foram analisadas secreções lácteas de 134 vacas leiteiras, perfazendo um total de 516 amostras. Na maioria das propriedades a ordenha era realizada de forma mecanizada. Das oito propriedades visitadas, apenas uma utilizava ordenha mecânica e manual. O sistema de criação era semi-intensivo e a alimentação à base de concentrado, volumoso e água proveniente de poços e açudes.

Inicialmente realizou-se a lavagem do teto com água e sabão, secagem com papel toalha e desinfecção do óstio do teto, utilizando álcool etílico a $70^{\circ} \mathrm{GL}$. Foram coletados aproximadamente $5 \mathrm{ml}$ de leite por quarto mamário em tubos rosqueados estéreis, identificados e enviados, sob refrigeração em caixas de material isotérmico contendo gelo reciclável, ao Laboratório de Doenças Infecto-Contagiosas da Universidade Federal Rural de Pernambuco, onde foram processadas.

No laboratório, as amostras foram previamente homogeneizadas e posteriormente, alíquotas de $0,1 \mathrm{~mL}$ foram semeadas em placas de Petri contendo ágar-base (Becton, Dickinson and Company, Sparks, USA) acrescido de 5\% de sangue desfibrinado de ovino. Em seguida procedeu-se à incubação em estufa bacteriológica a $37^{\circ} \mathrm{C}$ e as leituras foram realizadas 24,48 e 72 horas após. Inicialmente foram observadas as características micro-morfológicas das colônias à técnica do Gram. Constatada a presença de leveduras, procedeu-se ao processo de purificação, pela técnica de esgotamento em meio Sabouraud dextrose broth (Oxoid, Basingstoke, Hampshire, England). Para identificação, inicialmente foi realizada triagem em CHROMagar Candida ${ }^{\circledR}$ (Becton, Dickinson and Company, Sparks, USA), realizado estudo da micromorfologia em meio Ágar Fubá (Oxoid, Basingstoke, Hampshire, England) e teste de filamentação em soro humano, sendo utilizados os critérios propostos por Kreger-Van Rij (1984), Kurtzman \& Fell (1998) e De Hoog et al. (2000).

Para realização dos testes de eficiência dos desinfetantes, massas celulares dos isolados de leveduras foram transferidas para soluções salinas previamente preparadas na concentração correspondente ao tubo 1 da escala de Mc Farland. Alíquotas de $0,8 \mathrm{~mL}$ das soluções desinfetantes diluídas conforme especificações dos fabricantes foram distribuídas em tubos de ensaio estéreis. Em seguida, adicionaram-se alíquotas de $0,2 \mathrm{~mL}$ de leite estéril, correspondente a $10 \%$ de matéria orgânica. Posteriormente, adicionou-se 1,2 mL da suspensão fúngica e cronometraram-se os tempos 15", 30", 60", 300" e 600" de exposição para então realizar repique em caldo "Brain Heart Infusion" (Becton, Dickinson and Company, Sparks, USA). Esta mistura foi incubada a $37^{\circ} \mathrm{C}$ em estufa bacteriológica, num período de $48 \mathrm{~h}$ para verificar a turbidez do meio, formação de película na superfície ou de precipitado no 
fundo dos tubos. Os desinfetantes utilizados no teste foram: iodo a 0,57\% (Johnson Diversey, São Paulo, Brasil), ácido lático a 2,0\% (Weizur, Sorocaba, São Paulo, Brasil) clorexidine a 2,0\% (Weizur, Sorocaba, São Paulo, Brasil), cloro a 2,5\% (Shering-Plough, Wexford, Irlanda) e amônia quaternária 2,0\% (Sanphar, Campinas, São Paulo, Brasil). Apenas o cloro e a amônia quaternária necessitaram de diluição, e esta foi realizada conforme orientação dos fabricantes. Após a incubação, todas as amostras foram submetidas a repique em ágar Sabouraud e incubadas por mais $72 \mathrm{~h}$ para controle e confirmação da presença ou não do microrganismo testado. A ausência do crescimento das leveduras nas placas indicou a eficácia dos produtos testados nos diversos tempos de exposição a que as amostras foram submetidas (Costa 1998).

\section{RESULTADOS}

Das 516 amostras de leite analisadas foram isoladas 12 $(2,32 \%)$ leveduras, sendo 11 (91,66\%) do gênero Candida e $1(8,33 \%)$ Trichosporum sp. As espécies de Candida sp. identificadas neste estudo foram: $4(33,33 \%)$ C. tropicalis, 4 (33,33\%) C. krusei, 2 (16,67\%) C. parapsilosis, 1 (8,33\%) C. guilliermondii.

Das 12 amostras analisadas, apenas $2(16,67 \%)$ foram sensíveis ao cloro nos tempos 15" e 30", 3 (25\%) mostraram-se sensíveis ao mesmo desinfetante nos tempos 60 ", $300 "$ e $600 "$. Para o ácido láctico, $5(41,67 \%)$ amostras foram sensíveis em 15" de exposição, 7 (58,33\%) em 30", 8 $(66,67 \%)$ em 60" e 300" e 9 (75\%) em 600". Em relação ao composto de amônia, observou-se que $8(66,67 \%)$ isolados foram sensíveis nos tempos 15" e 30" e 11 (91,67\%) em $60 ", 300 "$ e $600 "$. 0 iodo obteve o segundo melhor resultado, observando-se que em $10(83,33 \%)$ amostras não houve crescimento no tempo 15", em $11(91,67 \%)$ não houve crescimento em 30" e a partir de 60" de exposição este produto foi eficiente nas $12(100 \%)$ amostras analisadas. 0 Clorexidine apresentou melhor resultado, mostrando-se eficaz nos $12(100 \%)$ isolados testados, nos diferentes tempos de exposição (Fig.1).

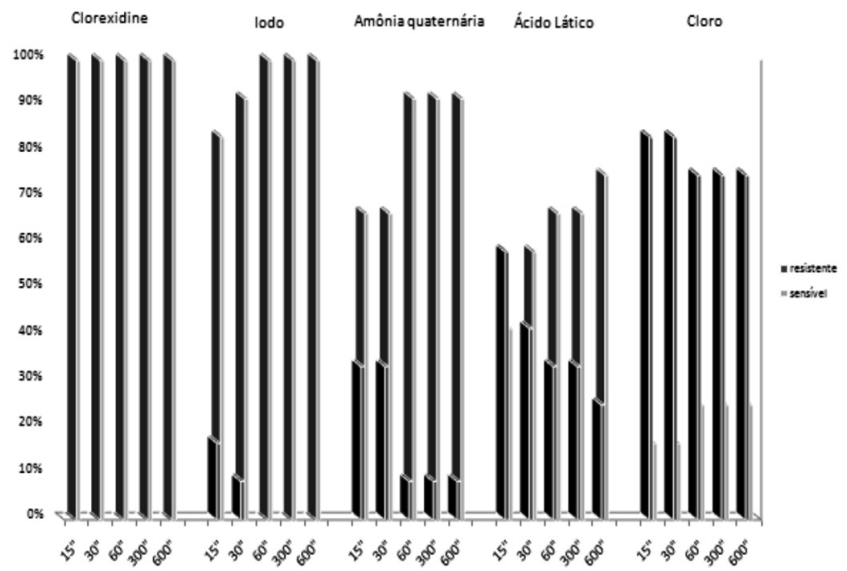

Fig.1. Eficácia in vitro dos desinfetantes utilizados no pré e pós-dipping em propriedades leiteiras frente a isolados de leveduras obtidos de leite de vaca com mastite.

\section{DISCUSSÃO}

Os resultados obtidos neste estudo estão de acordo com aqueles relatados anteriormente por Mota et al. (2004) que obtiveram $11(2,21 \%)$ isolados de fungos de um total de 496 amostras de leite de vaca com mastite no Estado de Pernambuco, sendo que $9(81,82 \%)$ eram do gênero Candida sp. A prevalência das mastites por fungos, nos Estados Unidos, variou entre 2 e $7 \%$ (Kirk \& Bartlett 1986). Entretanto, em países tropicais como o Brasil, este percentual pode ser mais elevado, chegando até $12 \%$ como relataram Costa et al. (1993). Ferreiro et al. (1985) observaram que o gênero Candida foi o mais prevalente nos casos de mastite micótica em levantamento realizado em nove municípios da Grande Porto Alegre. Na Bélgica, Lagneau et al. (1996) descreveram que as espécies de leveduras mais frequentemente encontradas em análises microbiológicas do leite foram a C. parapsilosis, C. guilliermondii, C. tropicalis, C. glabrata e T. asahii, podendo apresentar potencial patogênico.

Apesar de Candida albicans possuir maior patogenicidade em relação às demais espécies do gênero, outras espécies também já foram relatadas como patógenos em humanos imunossuprimidos (Wingard 1995). A espécie $C$. tropicalis possui considerável potencial patogênico como agente oportunista, principalmente quando o hospedeiro encontra-se neutropênico, diante da supressão da microbiota bacteriana pelo uso de antibióticos ou quando ocorrem danos na mucosa gastrintestinal (Colombo \& Guimarães 2003). Neste estudo os resultados encontrados indicam a importância de outras espécies do gênero como patógenos da glândula mamária de bovinos com mastite subclínica.

0 clorexidine é bastante empregado no tratamento de infecções superficiais de tetos de vacas, devido ao seu efeito antimicrobiano cumulativo e contínuo, permanecendo na pele no mínimo por $6 \mathrm{~h}$ (Spinosa et al. 2002). Bill (1997) estima sua ação residual em mais de 24 horas. Comparando-se com soluções de iodo, o clorexidine causa menor reação tecidual ou de pele nas diluições recomendadas (Phillips et al. 1991). Os resultados obtidos neste estudo confirmam aqueles encontrados por Medeiros et al. (2009), onde foi descrita maior atividade desinfetante in vitro do iodo e clorexidine frente a Staphylococcus aureus isolados de mastite na mesma região. A eficácia de $100 \%$ do clorexidine observada neste experimento associada às características antimicrobianas mencionadas sugerem que este desinfetante pode ser utilizado como uma das primeiras opções no pré e pós-dipping.

Compostos halógenos como iodo e cloro apresentam ação antimicótica no sentido indireto, atuando como fungistáticos ao modificar as condições locais (Lacaz \& Negro 1991, Arenas 1993). Especificamente o iodo é reconhecido como um efetivo anti-séptico, apresentando amplo espectro de ação sobre bactérias, fungos e vírus. No entanto, para serem eficazes, as concentrações devem ser ajustadas para os diferentes microrganismos (Gottardi 1991). Pedrini \& Margatho (2003) verificaram uma significativa atividade in vitro do iodo a $1 \%$ e $2 \%$ frente a microrganismos patogênicos isolados de casos de mastite clínica bovina. Entretanto, a partir de $1 \%$ ele é contra indicado em pele inflamada por causar ação irritante (Fox 1992). Estudos realizados por Jones (1998) demonstraram que soluções de iodo devem ser utilizadas em baixas concentrações $(0,5 \%$ ou menos) nos banhos de tetos para que não haja resíduos no leite. Hu 
et al. (1990) utilizaram produto a base de iodo a $0,5 \% \mathrm{em}$ um rebanho na China e verificaram uma redução de $50 \%$ na incidência de mastite subclínica. Considerando a grande diversidade dos agentes infecciosos envolvidos nos casos de mastite é importante dispor de agentes químicos que, numa única concentração possa servir em diferentes situações (pré e pós-dipping), mantendo suas propriedades desinfetantes, sem causar danos à saúde do animal ou a qualidade do produto. Além disso, a dinâmica de uma rotina de ordenha requer a utilização de produtos que produzam maior efeito desinfetante em menor tempo de atuação. Assim, os resultados obtidos neste estudo com o iodo a $0,57 \%$ atenderam parcialmente aos requisitos descritos, uma vez que apresentou $100 \%$ de eficácia in vitro, mas somente a partir de 60" de exposição.

Resultados parecidos, porém inferiores foram obtidos com amônia quaternária que também demonstrou ser mais eficaz a partir de 60 " de exposição. Entretanto, os percentuais de resistência foram de 33,33\% em até 30" de exposição, e nos tempos posteriores o percentual de resistência ainda se manteve em $8,33 \%$. Esses resultados podem estar relacionados à presença da matéria orgânica que determina uma diminuição acentuada da eficácia dos desinfetantes. Kich et al. (2004) realizaram avaliação da atividade antimicrobiana de seis desinfetantes comerciais frente a amostras de Salmonella typhimurium isoladas de suínos. Observaram que na presença de matéria orgânica, os produtos a base de amônia quaternária, hipoclorito de sódio $(0,1 \%)$, cloreto de benzalcônio e iodóforo, tiveram prejuízo em sua atividade.

No presente estudo, os isolados fúngicos mostraram alto percentual de resistência in vitro, na presença de $10 \%$ de matéria orgânica frente ao cloro. Os resultados para o cloro foram os mais insatisfatórios, podendo-se observar $83,33 \%$ de resistência em até 30 " de exposição e $75 \%$ de resistência nos tempos posteriores. De acordo com Bessems (1998) a concentração e o tempo de contato são fatores que podem interferir na ação do desinfetante, principalmente no que se refere aos produtos cujos componentes são à base de cloro. Segundo Fonseca \& Santos (2000) o cloro é um composto pouco tóxico, mas que apresenta ação irritante aos tecidos e tem sua ação reduzida pela presença de matéria orgânica. Hekmati \& Bradley (1979) descreveram que produtos à base de cloro se tornavam instáveis na presença de proteína com rápida inativação. Relataram ainda que a albumina, globulina e caseína são os componentes do leite que mais rapidamente inativam o cloro. Bill (1997) complementa citando que o cloro apresenta um elevado grau de afinidade por material orgânico como fezes, sangue e pus que podem neutralizar a sua ação microbicida na prática rotineira do pré e pós-dipping.

Em humanos, a utilização de ácidos orgânicos é uma das opções utilizadas como método químico na redução de $C$. albicans na superfície de próteses bucais (Lambert \& Kolstad 1986). Várias outras substâncias têm sido testadas por pesquisadores de diversas áreas visando à ação antimicrobiana e antifúngica destes ácidos (Pinto 2006). Muck et al. (1991) propuseram um modelo para examinar o papel das leveduras e bolores na deterioração do processo de silagem e utilizaram os ácidos acético e lático, não dissociados, para diminuir a taxa de crescimento dos fungos, contribuindo na estabilidade do processo de silagem. 0 ácido lático (2\%) é um produto que vem sendo comercializado como desinfetante no pré e pós-dipping. No entanto, neste estudo resultados relativos a este ácido orgânico não foram muito satisfatórios. Em 15" de exposição o percentual de resistência chegou a 58,33\%, decrescendo na medida em que aumentava o tempo de exposição.

Relata-se que na maioria das propriedades estudadas os desinfetantes são escolhidos por hábito de uso, facilidade de aplicação ou preço (Pedrini \& Margatho 2003). Entretanto, alguns estudos vêm indicando a importância de uma avaliação periódica dos desinfetantes utilizados no pré e pós-dipping, uma vez que vêm se percebendo maior dificuldade em controlar os microrganismos mais frequentemente envolvidos nos processos infecciosos da glândula mamária (Costa et al.1998, Medeiros et al. 2009).

\section{CONCLUSÕES}

Os resultados obtidos permitiram concluir que o clorexidine e o iodo apresentam atividade desinfetante significativamente superior ao cloro, frente a leveduras envolvidas nos processos infecciosos da glândula mamária em bovinos.

Avaliar periodicamente a atividade desinfetante dos produtos utilizados na rotina do pré e pós-dipping nas propriedades leiteiras frente aos microrganismos mais comumente envolvidos nos casos de mastite micótica é uma medida recomendada para a escolha adequada dos desinfetantes utilizados para esse fim.

\section{REFERÊNCIAS}

Andrade, S.F. 2002. Manual de terapêutica veterinária. $2^{\underline{a}}$ ed. Roca, São Paulo. 591p.

Arenas R. 1993. Micologia Medica Ilustrada. Nueva Editorial Interamericana, México, p.359-376.

Bessems E. 1998.The effect of pratical condition on the efficacy of desinfectants. Int. Biodeter. Biodegr. 41:177-183.

Bill R.L. 1997. Pharmacology for Veterinary Technicians. $2^{\mathrm{a}}$ ed. Mosby, St Louis. 291p.

Colombo,A. . \& Guimarães,T. 2003. Epidemiologia das infecções hematogênicas por Candida spp. Revta Soc. Bras. Med. Trop. 36:599-607.

Costa E.O. 1998. Importância da mastite na produção leiteira do Brasil. Revta Educ. Contin. CRMV-SP 1(1):3-9.

Costa E.O., Paula C.R, Gambale W., Costa Pires M.F., Coutinho S.D A. \& Castilho W. 1993. Survey of bovine mycotic mastitis in dairy herds in the State of São Paulo, Brazil. J. Mycopathol. 124:13-17.

Costa E.O., Ribeiro A.R., Watanabe E.T., Garino Jr F., Silva J.A.B. \& Thiers F.0. 1998. Avaliação in vitro dos desinfetantes utilizados na pós-ordenha (teat dipping) para controle da mastite bovina. Revta Napgama 1(1):1822

Cruz L.C.H. 1985. Micologia Veterinária: estudo e ensino. Imprensa Universitária, Rio de Janeiro. 89p.

De Hoog G.S., Guarro J., Gene J. \& Figueiras M.J. 2000. Atlas of Clinical Fungi. 6ª ed. CBS/Universitat Rovira, Virgili. 1126 p.

Ferreiro L., Ferreiro C.L.R., Bangel Jr J.J., Soares H.C., Moojen V.A. \& Fernandes J.C.T. 1985. Mastite bovina na Grande Porto Alegre, RS, Brasil: agentes etiológicos isolados durante o período 1982-1985. Arq. Fac. Vet. UFRGS 13:81-88.

Fonseca L.F.L. \& Santos M.V. 2000. Qualidade do leite e controle de mastite. Lemos Editorial, São Paulo. 175p. 
Fox L.K. 1992. Colonization by Staphylococcus aureus on chapped teat skin: effect of iodine and chorexidine postmilking disinfectants. J. Dairy Sci. 75:66-71.

Garcia M.E. \& Blanco J.L. 2000. Principales enfermidades fungicas que afectan a los animales domesticos. Revta Iberoam. Micol. 17:S2-S7.

Gottardi W.1991. Iodine and iodine compounds, p.152-166. In: Blocks S.S. (Ed.), Desinfection, Sterelization and Preservation. $4^{\text {th }}$ ed. Lea and Febiger, Philadelphia, Pa.

Hekmati M.\& Bradley Jr R.L. 1979. Effect of milk contituents on the persistence of sodium hypochorite sanitizer. J. Dairy Sci. 62:47-48.

Hu S., Fang 66W.H., Lu H.R., Jiang C., Zhu P., Ye J., Ye D. \& Ya H. 1990. Effect of teat dipping and dry cow therapy on mastitis in a commercial dairy herd in China. Prevent. Vet. Med. 10:91-96.

Jones G.M. 1998. Milking pratices recommended to assure milk quality and prevent mastitis. Dairy Science, Virginia Cooperative Extension, p.404-227.

Kich J.D. Borowski L., Silva V.S., Ramenzon M., Triques N., Kooler F.L. \& Cardoso M.R.I. 2004. Avaliação da atividade antibacteriana de seis desinfetantes comerciais frente a amostras de Salmonella typhimurium isoladas de suínos. Acta Sci. Vet. 32:33-39.

Kirk J.H.\& Bartlett P.C. 1986. Bovine mycotic mastitis. Compend. Contin. Educ. Pract. Vet. 8:106-110.

Kreger-Van Rij N.J.W. 1984. The Yeastes: a taxonomic study. $3^{\text {rd }}$ ed. Elsevier Science Publishers, Amsterdan. p.585-844.

Kurtzman C.P. \& Fell J.W. 1998. The yeast's: a taxonomic study. $4^{\text {th }}$ ed. Elsevier, New York, p.919-925.

Lacaz C.S. \& Negro G. 1991. Drogas antifúngicas: Terapêutica das micoses, p.616-651. In: Lacaz C.S., Porto E. \& Martins J.E.C (Eds), Micologia Médica: fungos, actinomicetos e algas de interesse médico. Savier, São Paulo.

Lagneau P.E., Lebtahi K. \& Swinne D. 1996. Isolation of yeasts from bovine milk in Belgium. J. Mycopathologia 135:99-102.

Lambert J.P.\& Kolstad R. 1986. Effect of a benzoic acid detergent gemicid on denture-borne Candida albicans. J. Prosthet. Dent. 55:699-700.

Medeiros E.S., Santos M.V., Pinheiro Júnior J.W., Faria E.B., Wanderley G.G., Teles J.A.A. \& Mota R.A. 2009. Avaliação in vitro da eficácia de desinfetantes comerciais utilizados no pré e pós-dipping frente amos- tras de Staphylococcus spp. isoladas de mastite bovina. Pesq. Vet. Bras. 29(1):71-75.

Mota R.A., Pinheiro Junior J.W., Silva D.R., Silveira N.S.S., Gomes S.M., Silva L.B.G., Cunha A.P., Rabelo S.S.A., Silva K.P.C. \& Barbosa M.A.G. 2004. Etiologia da mastite subclínica em bovinos da bacia leiteira do estado de Pernambuco. Revta Napgama 7(1):10-13.

Muck R.E., Pitt R.E. \& Leibensperger R.Y. 1991. A model of aerobic fungal growth in silage in microbial characteristics. Grass and Forage Sci. 46:283-299.

Pankey J.W., Eberhart R.J., Cuming A.L., Daggett R.D., Farnsworth R.J. \& McDuff C.K. 1984. Update on postmilking teat antisepsis. J. Dairy Sci. 67:1336.

Pedrini S.C.B. \& Margatho L.F.F. 2003. Sensibilidade de microrganismos patogênicos isolados de casos de mastite clínica em bovinos frente a diferentes tipos de desinfetantes. Arqs Inst. Biológico, São Paulo, 70:391-395.

Phillips M.F., Vasserur P.B. \& Gregory C.R. 1991. Clorhexedine diacetate versus povidone-iodine for preoperative preparation of the skin: a prospective randomized comparison in dogs and cats. J. Am. Anim. Hosp. Assoc. 27:105-108.

Pinto T.M.S. 2006. Vinagre como agente antimicrobiano no controle de Candida spp em portadores de prótese total. Dissertação Mestrado em Odontologia, Faculdade de Odontologia, Universidade de Taubaté, Taubaté, SP. 28p.

Quinn P.J. 1991. Disinfection and disease prevention in veterinary medicine, p.169-175. In: Ibid. (Ed.), Disinfection, Sterilization, and Preservation. $4^{\text {th }}$ ed. Lea and Febiger, Philadelphia,

Rey J.E., Jimenez E. \& Franjo C. 1997. Diagnóstico de las mamitis bovinas por microcalorimetria. Med. Vet. 14:162-168.

Sá F.V. 1996. As vacas leiteiras. Clássica Editora, Lisboa, p.287-325.

Spanamberg A., Sanches E.M.C., Santurio J.M. \& Ferreiro L. 2009. Mastite micótica em ruminantes causada por leveduras. Ciência Rural 39(1):282-290.

Spinosa H.S., Gorniak S.L. \& Bernadini M.M. 2002. Farmacologia Aplicada à Medicina Veterinária. $2^{\underline{a}}$ ed. Guanabara Koogan, Rio de Janeiro. 489p.

Wingard J.R. 1995. Importance of Candida species other than C. albicans as pathogens in oncology patients. Clinical Infectious Diseases 20: 115-125. 